\title{
Presynaptic Control of Rapid Estrogen Fluctuations in the Songbird Auditory Forebrain
}

\author{
Luke Remage-Healey, ${ }^{1,3}$ Stephanie Dong, ${ }^{1}$ Nigel T. Maidment, ${ }^{2}$ and Barney A. Schlinger ${ }^{1}$ \\ ${ }^{1}$ Department of Integrative Biology and Physiology, and Laboratory of Neuroendocrinology, Brain Research Institute, and ${ }^{2} \mathrm{Hatos}$ Center for \\ Neuropharmacology, University of California, Los Angeles, Los Angeles, California 90095, and ${ }^{3}$ Neuroscience and Behavior Program, Center for \\ Neuroendocrine Studies, University of Massachusetts, Amherst, Massachusetts 01003
}

Within the CNS of vertebrates, estrogens can directly modulate neural circuits that govern a wide range of behaviors, including feeding, spatial navigation, reproduction, and auditory processing. The rapid actions of estrogens in brain (seconds to minutes) have become well established, but it is unclear how estrogens are synthesized and released within restricted temporal and spatial domains in neural circuits. Anatomical localization of the estrogen synthesis enzyme (aromatase) within presynaptic terminals suggests that neuroestrogens can be synthesized directly at the neuronal synapse. A consequent prediction follows that synaptic estrogen production is controlled via classical electrochemical events in neurons. Here, we present evidence that acute fluctuations in local neuroestrogen levels in the forebrain of the zebra finch depend on calcium influx within presynaptic terminals. In vivo experiments using microdialysis linked to a sensitive estrogen ELISA showed that local forebrain neuroestrogens were both suppressed by potassium-evoked excitation and upregulated during 30 min periods of extracellular calcium depletion in a region enriched with presynaptic aromatase. Furthermore, potassium-evoked changes in local neuroestrogens were blocked by targeted delivery of the voltage-gated calcium channel blocker $\omega$-conotoxin GVIA. Together, these experiments indicate that neuroestrogens are controlled by specific, depolarization-sensitive, calcium-dependent events within forebrain presynaptic terminals.

\section{Introduction}

Classical neurotransmitter and neuropeptide release is dependent on depolarization-induced opening of presynaptic voltagegated $\mathrm{Ca}^{2+}$ channels (VGCCs) (Catterall and Few, 2008). Like neurotransmitters and neuropeptides, steroid hormones are synthesized within brain circuits and can act as fast modulators of neural excitability and behavior. In particular, estrogens can alter neuronal excitability within seconds to minutes in the amygdala, hippocampus, striatum, hindbrain, and cortex (Thompson and Moss, 1994; Becker, 1999; Mhyre and Dorsa, 2006; RemageHealey and Bass, 2007; Woolley, 2007; Grassi et al., 2009; Herbison, 2009; Kelly and Rønnekleiv, 2009). Thus, brain-derived estrogens are increasingly considered genuine neuromodulators (Balthazart and Ball, 2006; Remage-Healey and Bass, 2006; Garcia-Segura, 2008). However, it is unclear whether neuroestrogen production is controlled via electrochemical events that are the hallmark of neurotransmitter-based cell-cell communication. In particular, despite the great potential for estrogens as neurotherapeutic agents (Harden and MacLusky, 2004; Iivonen

\footnotetext{
Received Feb. 1, 2011; revised May 17, 2011; accepted May 31, 2011.

Author contributions: L.R.-H., N.T.M., and B.A.S. designed research; L.R.-H. and S.D. performed research; L.R.-H. and S.D. analyzed data; L.R.-H. and B.A.S. wrote the paper.

This research was supported by NINDS Grants F32NS058009, K99/R00NS066179, and NIMH Grant 061994. We thank Andrew Chao, Sonja Smith, and Jenna McHale for technical support, and Felix Schweizer for thoughtful discussion.

Correspondence should be addressed to Luke Remage-Healey, Neuroscience and Behavior Program, Center for Neuroendocrine Studies, University of Massachusetts, Amherst, MA 01003. E-mail: healey@cns.umass.edu.

DOI:10.1523/JNEUROSCI.0566-11.2011

Copyright $\odot 2011$ the authors $\quad 0270-6474 / 11 / 3110034-05 \$ 15.00 / 0$
}

et al., 2004), the spatiotemporal control mechanisms for neuronal estrogen production are largely unknown.

Biochemical and anatomical evidence from songbirds, rodents, and primates indicates that the estrogen synthetic enzyme aromatase is expressed within presynaptic terminals in the forebrain (Schlinger and Callard, 1989; Naftolin et al., 1996; Hojo et al., 2004; Peterson et al., 2005; Rohmann et al., 2007; Srivastava et al., 2010). This localization has driven speculation that neuroestrogen production is controlled by fast and localized mechanisms at the presynaptic terminal. In support of this idea, the biochemical activity of the aromatase enzyme is differentially regulated in synaptic versus somal cellular compartments in the forebrain of songbirds (Rohmann et al., 2007; Remage-Healey et al., 2009). Despite these advances, tissue micropunches for enzymatic analysis have limited spatial resolution (Cornil et al., 2006; RemageHealey et al., 2009), and measurement of biochemical enzyme activity remains an indirect assessment of real-time fluctuating neuroestrogen levels.

A recently optimized steroid microdialysis system in songbirds enables the precise measurement and manipulation of local neuroestrogen fluctuations within discrete forebrain nuclei in vivo (Remage-Healey et al., 2008, 2010). Experimental evidence using this approach shows that forebrain neuroestrogen levels can change rapidly in behavioral contexts, and that these changes are restricted to nuclei such as the caudomedial nidopallium (NCM; the avian secondary auditory cortex), which contains enriched presynaptic aromatase (Remage-Healey et al., 2008). Here, we test the hypothesis that neuroestrogen levels in the songbird forebrain are regulated by electrochemical events (summed 
over $30 \mathrm{~min}$ ) within the NCM. Further, we determine whether these relatively acute changes in neuroestrogens depend on voltage-gated events within NCM presynaptic terminals.

\section{Materials and Methods}

Subjects. Adult male zebra finches ( $>130 \mathrm{~d}$ old $)$ were from the University of California, Los Angeles (UCLA), breeding colony (14/10 h light/dark cycle). Animal protocols were approved by the UCLA Chancellor's Committee on Animal Care and Use. In vivo microdialysis has been previously optimized in this species for the measurement of neurosteroids and dopamine (Sasaki et al., 2006; Remage-Healey et al., 2008, 2010). Animals recover quickly from surgery and are required to meet observational criteria for normal feeding, drinking, and social behaviors at experiment onset.

Surgery. All surgical procedures followed those outlined previously for cannula implantation (Remage-Healey et al., 2008, 2010). Food deprivation occurred for $1-3 \mathrm{~h}$ before intracranial surgery to prevent complications during the procedure. Birds were stabilized in a custom stereotaxic device (head angle, $45^{\circ}$; Herb Adams Engineering) and kept warm with a heating pad. Lidocaine ( $2 \%$ in ethanol) was injected under the scalp, and feathers were removed to expose the skull area dorsal to NCM. A 26 gauge syringe needle tip (BD Biosciences) was used to make a small incision in the outer and inner skull layers above NCM, and the dura mater was carefully opened. A CMA-7 microdialysis cannula (CMA Microdialysis) was implanted into NCM and cemented in place with cyanoacrylate and dental cement (Perm Reline/Repair Resin; Coltène/Whaledent). The scalp incision was sealed with cyanoacrylate, and birds were returned to individual sound attenuation chambers for postsurgical recovery $(\sim 5 \mathrm{~d})$.

Microdialysis. Before an experimental session, microdialysis probes, swivels, and fluorinated ethylene propylene tubing were each rinsed with ethanol and doubly distilled $\mathrm{H}_{2} \mathrm{O}$, and prefilled with aCSF $(199 \mathrm{~mm} \mathrm{NaCl}$; $26.2 \mathrm{~mm} \mathrm{NaHCO}$; $2.5 \mathrm{~mm} \mathrm{KCl} ; 1.0 \mathrm{~mm} \mathrm{MgS04;} 2.5 \mathrm{~mm} \mathrm{CaCl} ; 11.0 \mathrm{~mm}$ glucose; $1 \%$ bovine serum albumin; $\mathrm{pH}$ 7.4). Microdialysis probes (CMA 7, cuprophane; CMA Microdialysis) were implanted at least $12 \mathrm{~h}$ before an experimental sampling session to allow behavioral adaptation and for acute implantation-induced phenomena to subside. The probe obdurator was removed from the guide cannula and replaced by a CMA-7 microdialysis probe that had been prefilled with aCSF at a flow rate of 2.0 $\mu \mathrm{l} / \mathrm{min}$ (PHD22/2000 syringe pump; Harvard Apparatus) and optimized for the detection of neuroestrogens (Remage-Healey et al., 2008). All samples in this study were collected at $30 \mathrm{~min}$ intervals (corrected for tubing length delay), and immediately sealed and stored at $-80^{\circ} \mathrm{C}$. At the end of each experimental session, birds were killed via isoflurane overdose and perfused through the heart with $0.9 \%$ PBS followed by $4 \%$ paraformaldehyde. Cannulae and probes were removed after perfusion to preserve the implantation site. Brains were cryoprotected and sectioned at $50 \mu \mathrm{m}$ thickness, and sections were mounted onto superfrost slides (Fisher Scientific), air dried, stained with thionin, and photographed under light microscope to verify probe placement. All results in this study are from histologically confirmed probes placed within NCM.

ELISA. Samples were analyzed for fluctuating $17 \beta$-estradiol $\left(\mathrm{E}_{2}\right)$ levels using a previously optimized protocol (Remage-Healey et al., 2008) with a commercially available ELISA (Cayman Chemical). All pharmacological experiments (outlined below) required reverse delivery (retrodialysis) of the dissolved drug in aCSF, and all retrodialysis solutions were therefore analyzed alongside samples to determine drug cross-reactivity with the assay. No retrodialysis solution used in this study exhibited cross-reactivity. Assay runs differed in dynamic range of the standard curve (based on variable antibody lots from the commercial provider), therefore relative changes in $\mathrm{E}_{2}$ levels over time within experiments (and not absolute differences in $\mathrm{E}_{2}$ levels between experiments) are the focus of our analyses. All samples from each animal were run in the same assay to provide accurate within-subject comparisons. For comparison purposes, dashed lines in figures represent the average ELISA background reading for aCSF alone (i.e., perfusate before dialysis).

Elevated $\mathrm{K}^{+}$versus $\mathrm{Ca}^{2+}$-free retrodialysis experiments. A prior study observed acute transient suppressive effects of the excitatory transmitter glutamate on local $\mathrm{E}_{2}$ levels within NCM using retrodialysis (Remage-
Healey et al., 2008). To test whether electrochemical excitation/suppression would be associated with similarly rapid regulation of local $\mathrm{E}_{2}$ levels, an elevated $\mathrm{K}^{+}$versus $\mathrm{Ca}^{2+}$ removal paradigm was used. Retrodialysis of aCSF with elevated $\mathrm{K}^{+}$ion concentrations (100 mm; "high $\mathrm{K}^{+}$”) induces sustained depolarization events associated with classical neurotransmitter release, while removal of extracellular $\mathrm{Ca}^{2+}$ (i.e., depleting $\mathrm{Ca}^{2+}$ from aCSF perfusate) is associated with suppression of synaptic transmission (Westerink, 1995). Importantly, along with increased excitation, high $\mathrm{K}^{+}$treatment can induce depolarization block in vitro (Lian et al., 2003), yet in vivo high $\mathrm{K}^{+}$treatment drives sustained neurotransmitter release over 30-40 min in zebra finch forebrain (Sasaki et al., 2006). For the high $\mathrm{K}^{+}$experiment $(n=7)$, normal aCSF was perfused into NCM for two successive $30 \mathrm{~min}$ baseline sampling periods (pre1 and pre2), and the perfusion solution was then switched to high $\mathrm{K}^{+}$aCSF solution for 30 $\mathrm{min}$, followed by three $30 \mathrm{~min}$ washout periods of normal aCSF replacement (wash 1,2 , and 3 ). For the $\mathrm{Ca}^{2+}$ experiment $(n=9)$, normal aCSF was perfused into NCM for two successive $30 \mathrm{~min}$ baseline sampling periods (pre1 and pre2), and the perfusion solution was then switched to $\mathrm{a} \mathrm{Ca}^{2+}$-free aCSF solution for three successive 30 min periods $\left(\mathrm{Ca}^{2+}\right.$. free 1, 2, and 3; a paradigm that induces steady removal of local extracellular $\mathrm{Ca}^{2+}$ ) (Westerink, 1995; Sasaki et al., 2006), followed by two $30 \mathrm{~min}$ washout periods of normal aCSF replacement (wash 1 and 2).

Conotoxin experiments. The results of the elevated $\mathrm{K}^{+}$versus $\mathrm{Ca}^{2+}$ removal experiments were consistent with high $\mathrm{K}^{+}$-induced depolarization causing immediate $\mathrm{Ca}^{2+}$ influx through VGCCs within synaptic terminals in NCM. Because aromatase is expressed in presynaptic terminals in NCM (Peterson et al., 2005), and the enzymatic activity of aromatase is rapidly attenuated by $\mathrm{Ca}^{2+}$-induced phosphorylation in quail hypothalamic explants (Balthazart et al., 2003), we reasoned that high $\mathrm{K}^{+}$suppressed $\mathrm{E}_{2}$ levels via voltage-gated $\mathrm{Ca}^{2+}$ influx into presynaptic terminals in NCM. To specifically test this hypothesis, we retrodialyzed into NCM the $\mathrm{Ca}^{2+}$ channel-blocker $\omega$-conotoxin GVIA (Sigma; doses: 0,1 and $10 \mu \mathrm{M} ; n=4$ each), which specifically blocks presynaptic VGCCs in vertebrates (Stanley and Goping, 1991; Yawo and Momiyama, 1993; Olivera et al., 1994). After conotoxin pretreatment, NCM was stimulated with high $\mathrm{K}^{+}$to induce suppression of local $\mathrm{E}_{2}$ levels. Despite its high molecular weight $(3037 \mathrm{Da})$, which limits diffusion across the dialysis membrane (6000 Da cutoff), $\omega$-conotoxin GVIA has been used previously in retrodialysis experiments to test in vivo regulation of classical neurotransmitters (Okada et al., 1998; Liu et al., 2001; Belardetti et al., 2009), indicating its suitability for this experimental approach. Two successive $30 \mathrm{~min}$ baseline sampling periods (pre1, pre2) established baseline $\mathrm{E}_{2}$ levels to 0 , 1, or $10 \mu \mathrm{M} \omega$-conotoxin dissolved in aCSF (Fig. 2; for clarity only the pre 2 period is presented as "pre"), and the perfusion solution was then switched to high $\mathrm{K}^{+}$aCSF for a 30 min treatment period (maintaining conotoxin dose), followed by three successive 30 min washout periods with normal aCSF (wash 1, 2, and 3). A separate experiment determined the effects of $\omega$-conotoxin alone on local $\mathrm{E}_{2}$ levels in NCM ( $n=4$ for 1 and $10 \mu \mathrm{M} \omega$-conotoxin doses each), following a similar treatment design (two successive periods of $30 \mathrm{~min}$ aCSF followed by two successive periods of either 1 or $10 \mu \mathrm{M} \omega$-conotoxin in aCSF).

\section{Results}

\section{Elevated $\mathrm{K}^{+}$versus $\mathrm{Ca}^{2+}$-free retrodialysis experiments}

Similar to findings with glutamate-evoked excitation (RemageHealey et al., 2008), retrodialysis of aCSF containing highconcentration $\mathrm{K}^{+}$ions caused transient suppression of local $\mathrm{E}_{2}$ levels in NCM (Fig. 1A) $(N=7)$. The nonparametric repeatedmeasures Friedman test revealed an overall effect of high $\mathrm{K}^{+}$ treatment on local $\mathrm{E}_{2}$ levels $\left(\chi^{2}=13.66 ; p=0.017\right)$. Wilcoxon signed rank post hoc tests determined that local $\mathrm{E}_{2}$ levels during the 30 min period of high $\mathrm{K}^{+}$treatment were significantly suppressed relative to the preceding baseline period $(Z=-2.521$; $p=0.012$ for pre $\left.2 \mathrm{vs} \mathrm{K}^{+}\right)$. Therefore, a period of presumed local depolarization events (which is associated with rapid neurotransmitter release in the forebrain in this same species) (Sasaki et al., 2006) caused a rapid suppression of local $E_{2}$ levels within NCM, 


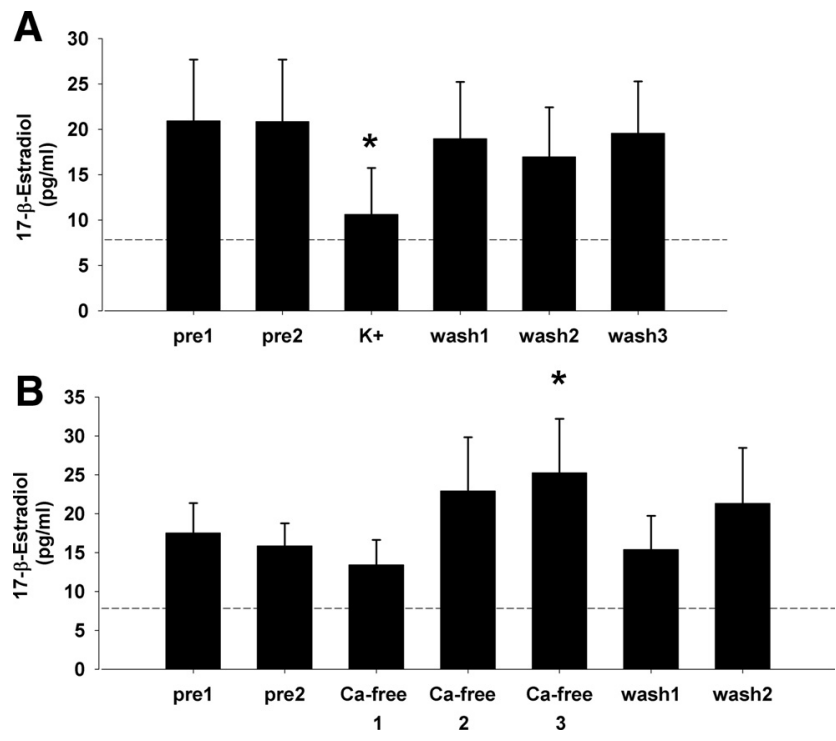

Figure 1. A, Local $\mathrm{E}_{2}$ levels in NCM in vivo are suppressed during potassium-evoked excitation, consistent with a depolarization-sensitive electrochemical mechanism of neuroestrogen control. Relative to aCSF pretreatment periods, 30 min of $100 \mathrm{~mm} \mathrm{~K}^{+}$aCSF caused a relatively rapid suppression of local $\mathrm{E}_{2}$ levels. $N=7$. B. Depletion of local $\mathrm{Ca}^{2+}$ levels in NCM causes a steady increase in local $\mathrm{E}_{2}$ levels, consistent with $\mathrm{Ca}^{2+}$-mediated mechanism of neuroestrogen control. $N=9$; each time bin $=30$ min. ${ }^{*} p<0.05$ for within-subject comparison to baseline pre2 sampling period. Dashed line represents the average ELISA background reading for aCSF alone.

consistent with an activity-dependent regulation of neuroestrogen levels.

Conversely, retrodialysis of $\mathrm{Ca}^{2+}$-free aCSF (which attenuates classical neurotransmitter release in the forebrain in this same species) (Sasaki et al., 2006) caused gradual increases in local $\mathrm{E}_{2}$ levels in NCM (Fig. $1 B)(N=9)$. The nonparametric repeatedmeasures Friedman test revealed an overall effect of $\mathrm{Ca}^{2+}$ removal treatment on local $\mathrm{E}_{2}$ levels $\left(\chi^{2}=7.9 ; p=0.048\right)$. Wilcoxon signed rank post hoc tests determined that local $\mathrm{E}_{2}$ levels were significantly elevated by the third $\mathrm{Ca}^{2+}$-free treatment period $(Z=2.547 ; p=0.011)$ relative to baseline (normal $\mathrm{Ca}^{2+}$. containing aCSF in pre2 sample). Once extracellular $\mathrm{Ca}^{2+}$ levels were restored (wash 1), local $\mathrm{E}_{2}$ levels returned to baseline $(p<$ 0.05 for the transition from Ca-free 3 to wash 1). Therefore, removal of extracellular $\mathrm{Ca}^{2+}$ levels within NCM was associated with a release of inhibition of local $\mathrm{E}_{2}$ levels, consistent with a $\mathrm{Ca}^{2+}$-dependent suppression of aromatase enzyme activity in NCM neurons.

\section{Conotoxin experiments}

Based on the above results, we reasoned that high $\mathrm{K}^{+}$suppressed $\mathrm{E}_{2}$ levels via voltage-gated $\mathrm{Ca}^{2+}$ influx into presynaptic terminals in NCM. To specifically test this hypothesis, we retrodialyzed into NCM the $\mathrm{Ca}^{2+}$ channel blocker $\omega$-conotoxin, which specifically blocks presynaptic VGCCs in vertebrates (Stanley and Goping, 1991; Yawo and Momiyama, 1993; Koyano et al., 1996). The nonparametric repeated-measures Friedman test does not compute multifactorial analyses, so repeated-measures ANOVA was used for analysis of the effects of conotoxin dose and time, with repeated measures over time. Two-way ANOVA revealed an overall effect of $\omega$-conotoxin treatment over time (Fig. 2$)(F=$ 6.873; df $=6,54 ; p<0.0001)$, and a significant conotoxin dose $^{\star}$ time interaction $(F=2.393 ; \mathrm{df}=12,54 ; p=0.015)$. In the absence of conotoxin pretreatment (dose $=0 \mu \mathrm{M})$, post hoc tests

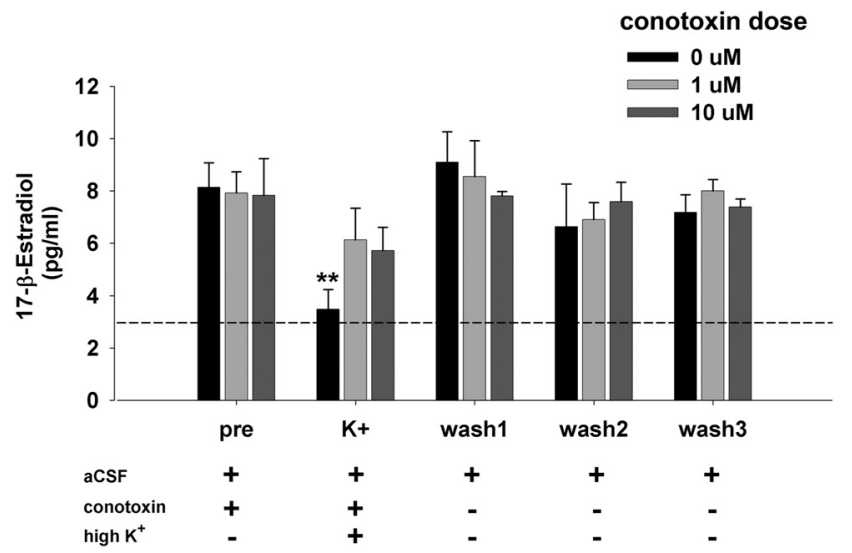

Figure 2. Acute in vivo changes in local $\mathrm{E}_{2}$ levels in NCM are dependent on presynaptic VGCCs. Presynaptic inhibition of VGCCs via retrodialysis of $\omega$-conotoxin disrupts the suppressive effect of potassium-evoked excitation on local $\mathrm{E}_{2}$ levels. $N=4 /$ group; each time bin $=30 \mathrm{~min}$. ${ }^{* *} p<0.005$ for within-subject comparison to pre-sampling period. Dashed line represents the average ELISA background reading for aCSF alone.

revealed a significant suppression of local $\mathrm{E}_{2}$ levels during the high $\mathrm{K}^{+}$treatment period $\left(\mathrm{Z}=8.961 ; p=0.003\right.$ for pre vs $\left.\mathrm{K}^{+}\right)$, matching our earlier findings in the high $\mathrm{K}^{+}$experiment above. By contrast, for both doses of $\omega$-conotoxin $(1$ and $10 \mu \mathrm{M})$ post hoc tests revealed no significant effect of high $\mathrm{K}^{+}$treatment on local $\mathrm{E}_{2}$ levels in NCM when compared with pretreatment baseline ( $p>0.57$ for both tests). The Mann-Whitney $U$ test showed a nonsignificant trend for between-group differences during the high $\mathrm{K}^{+}$treatment period $(Z=1.732 ; p=0.083$ for both 1 and 10 $\mu \mathrm{M}$ vs $0 \mu \mathrm{M})$. During three successive $30 \mathrm{~min}$ aCSF washout periods, local $\mathrm{E}_{2}$ levels remained at baseline in all three treatment groups. In a separate experiment comparing two 30 min periods of $\omega$-conotoxin treatment with two aCSF control periods, there was no effect of conotoxin alone on local $\mathrm{E}_{2}$ levels in NCM (treatment: $F=1.467 ; p=0.269$; treatment ${ }^{\star}$ dose: $F=2.034 ; p=0.173$; data not shown). In summary, presynaptic VGCC blockade eliminated the rapid suppressive effect of high $\mathrm{K}^{+}$-induced depolarization on local $\mathrm{E}_{2}$ levels in NCM.

\section{Discussion}

This study presents direct evidence that neuroestrogen fluctuations are dependent on summed (30 min) electrochemical events within presynaptic terminals in the zebra finch NCM. These findings are broadly significant in at least two ways. First, direct measurement of forebrain $\mathrm{E}_{2}$ levels shows that neuroestrogen flux is under the control of classical depolarization-dependent phenomena, consistent with the hypothesis that neuroestrogens can fluctuate and modulate cortical information flow at a relatively fast time scale (i.e., $\leq 30 \mathrm{~min}$ ). Second, results with the VGCC blocker $\omega$-conotoxin are consistent with the hypothesis that the electrochemical control of neuroestrogens depends on $\mathrm{Ca}^{2+}$. dependent events localized to the neuronal synapse.

Despite the excellent target specificity of $\omega$-conotoxin for VGCC blockade in presynaptic terminals (Stanley and Goping, 1991; Yawo and Momiyama, 1993), our in vivo retrodialysis approach most likely resulted in incomplete diffusion into the entire local NCM neuronal population, and our $30 \mathrm{~min}$ exposure/ sampling regime may have produced consequences secondary to VGCC blockade. Additionally, local conotoxin retrodialysis could block presynaptic VGCCs in NCM aromatase+ neurons and their local afferents. We are therefore unable to exclude the possibility that our results depend in part on modulation of af- 
ferent input to NCM neuroestrogenic cells. Although a direct effect of conotoxin on estrogenic presynaptic terminal VGCCs is the most parsimonious explanation, further in vitro experiments can help distinguish among these hypotheses. Furthermore, improving the sensitivity of in vivo steroid dialysis would narrow the relatively coarse temporal resolution of neuroestrogen flux presented here (i.e., within $30 \mathrm{~min}$ ), providing a better temporal fidelity match with the momentary changes in neuronal activity that occur in behaving animals.

Accumulating physiological evidence has demonstrated that changes in neuronal synthesis of $\mathrm{E}_{2}$ and/or changes in brain aromatase activity can occur within minutes of stimulation. For example, biochemical activity of the aromatase enzyme in hypothalamic explants is rapidly attenuated following copulatory behavior in Japanese quail (Cornil et al., 2005, 2006). Moreover, in vitro studies show that glutamatergic agonists rapidly alter aromatase activity in the hypothalamus and $\mathrm{E}_{2}$ production in the hippocampus (Balthazart et al., 2006; Mukai et al., 2006), and in vivo microdialysis reveals that $\mathrm{E}_{2}$ production in the auditory forebrain is acutely glutamate-sensitive (Remage-Healey et al., 2008). Together, this body of work has indicated that $\mathrm{E}_{2}$ is synthesized locally and changes rapidly in discrete brain nuclei.

The present study now extends these findings by directly revealing a candidate electrochemical mechanism for presynaptic control of brain $\mathrm{E}_{2}$ levels. Accordingly, the updated current working model for rapid neuroestrogen synthesis and action is as follows: (1) neuronal aromatase is expressed and biochemically active in presynaptic terminals (Schlinger and Callard, 1989; Naftolin et al., 1996; Peterson et al., 2005; Rohmann et al., 2007; Remage-Healey et al., 2009); (2) brain aromatase activity and estradiol production are controlled by excitatory inputs, including glutamatergic activation (Balthazart et al., 2006; Mukai et al., 2006; Remage-Healey et al., 2008); (3) neuronal estrogen production can be controlled by an excitatory, VGCC-dependent mechanism within presynaptic terminals (the present study); (4) extranuclear estrogen receptors occur in both presynaptic boutons and in dendritic processes indicative of a perisynaptic modulatory capacity (Blaustein et al., 1992; Milner et al., 2001; Xu et al., 2003; Hart et al., 2007); and (5) rapid effects of estrogens on neuronal firing properties can be both presynaptic and postsynaptic (i.e., altered intrinsic bursting states, postsynaptic currents, and/or potentiation) (Dufy et al., 1979; Wong and Moss, 1992; Rudick and Woolley, 2001; Grassi et al., 2009; Tremere et al., 2009; Remage-Healey et al., 2010). Thus, the current study provides a critical link in the logical chain of events for the modulatory control of neuroestrogen synthesis and action within brain circuits.

Our results show that $\omega$-conotoxins do not exert constitutive effects on $E_{2}$ levels, in the absence of K-induced depolarization. However, local $\mathrm{E}_{2}$ levels are elevated in response to depletion of extracellular $\mathrm{Ca}^{2+}$ concentrations, a manipulation that can affect $\mathrm{Ca}^{2+}$ balance at several subcellular loci within neurons. Based on these observations, we predict that other $\mathrm{Ca}^{2+}$-dependent events in aromatase-positive neurons can regulate $\mathrm{E}_{2}$ synthesis independent of depolarization phenomena and VGCCs. Candidate molecular mechanisms include intracellular $\mathrm{Ca}^{2+}$-dependent second messengers such as protein kinase A (PKA), PKC, and CAM kinase, which have been implicated in the rapid control of somal aromatase activity (Balthazart et al., $2003,2005)$ and may in fact rapidly control neural aromatase in songbirds and other vertebrates.

In mammalian neurons, $\omega$-conotoxins specifically inhibit "N-type" $\mathrm{Ca}^{2+}$ channels that contain the $\alpha_{1 \mathrm{~B}}$ subunit (Olivera et al., 1994). Some caution is warranted in concluding that $\omega$-conotoxin-sensitive phenomena in avian brain are due to $\mathrm{N}$-type $\mathrm{Ca}^{2+}$ channels specifically since the subunit composition of $\mathrm{Ca}^{2+}$ channels has not been fully characterized in birds (Olivera et al., 1994; Lachica et al., 1995; Wada et al., 2003). Importantly, however, $\omega$-conotoxin blockade of presynaptic $\mathrm{Ca}^{2+}$ channels is a conserved feature of the vertebrate CNS, and $\omega$-conotoxins have been effective at presynaptic VGCC blockade in the avian auditory brainstem and midbrain (Stanley and Goping, 1991; Yawo and Momiyama, 1993; Lu and Rubel, 2005; Lu, 2009). It is therefore reasonable to expect that presynaptic VGCCs are conotoxin sensitive in the zebra finch auditory forebrain.

We believe that these findings begin to characterize a fundamental mechanism for rapid, presynaptic estrogen provisioning within neural circuits. The precise control of estrogen delivery to perisynaptic targets provides clues regarding the function of aromatase-positive fibers and boutons that are found throughout the CNS of vertebrates.

\section{References}

Balthazart J, Ball GF (2006) Is brain estradiol a hormone or a neurotransmitter? Trends Neurosci 29:241-249.

Balthazart J, Baillien M, Charlier TD, Ball GF (2003) Calcium-dependent phosphorylation processes control brain aromatase in quail. Eur J Neurosci 17:1591-1606.

Balthazart J, Baillien M, Ball GF (2005) Interactions between kinases and phosphatases in the rapid control of brain aromatase. J Neuroendocrinol 17:553-559.

Balthazart J, Baillien M, Ball GF (2006) Rapid control of brain aromatase activity by glutamatergic inputs. Endocrinology 147:359-366.

Becker JB (1999) Gender differences in dopaminergic function in striatum and nucleus accumbens. Pharmacol Biochem Behav 64:803-812.

Belardetti F, Ahn S, So K, Snutch TP, Phillips AG (2009) Block of voltagegated calcium channels stimulates dopamine efflux in rat mesocorticolimbic system. Neuropharmacology 56:984-993.

Blaustein JD, Lehman MN, Turcotte JC, Greene G (1992) Estrogen receptors in dendrites and axon terminals in the guinea pig hypothalamus. Endocrinology 131:281-290.

Catterall WA, Few AP (2008) Calcium channel regulation and presynaptic plasticity. Neuron 59:882-901.

Cornil CA, Dalla C, Papadopoulou-Daifoti Z, Baillien M, Dejace C, Ball GF, Balthazart J (2005) Rapid decreases in preoptic aromatase activity and brain monoamine concentrations after engaging in male sexual behavior. Endocrinology 146:3809-3820.

Cornil CA, Ball GF, Balthazart J (2006) Functional significance of the rapid regulation of brain estrogen action: where do the estrogens come from? Brain Res 1126:2-26.

Dufy B, Vincent JD, Fleury H, Du Pasquier P, Gourdji D, Tixier-Vidal A (1979) Dopamine-inhibition of action potentials in a prolactin secreting cell-line is modulated by estrogen. Nature 282:855-857.

Garcia-Segura LM (2008) Aromatase in the brain: not just for reproduction anymore. J Neuroendocrinol 20:705-712.

Grassi S, Frondaroli A, Dieni C, Scarduzio M, Pettorossi VE (2009) Longterm potentiation in the rat medial vestibular nuclei depends on locally synthesized 17 $\beta$-estradiol. J Neurosci 29:10779-10783.

Harden C, MacLusky NJ (2004) Aromatase inhibition, testosterone, and seizures. Epilepsy Behav 5:260-263.

Hart SA, Snyder MA, Smejkalova T, Woolley CS (2007) Estrogen mobilizes a subset of estrogen receptor- $\alpha$-immunoreactive vesicles in inhibitory presynaptic boutons in hippocampal CA1. J Neurosci 27:2102-2111.

Herbison AE (2009) Rapid actions of oestrogen on gonadotropin-releasing hormone neurons; from fantasy to physiology? J Physiol 587:5025-5030.

Hojo Y, Hattori TA, Enami T, Furukawa A, Suzuki K, Ishii HT, Mukai H, Morrison JH, Janssen WG, Kominami S, Harada N, Kimoto T, Kawato S (2004) Adult male rat hippocampus synthesizes estradiol from pregnenolone by cytochromes P45017 alpha and P450 aromatase localized in neurons. Proc Natl Acad Sci U S A 101:865-870.

Iivonen S, Corder E, Lehtovirta M, Helisalmi S, Mannermaa A, Vepsäläinen S, 
Hänninen T, Soininen H, Hiltunen M (2004) Polymorphisms in the CYP19 gene confer increased risk for Alzheimer disease. Neurology 62:1170-1176.

Kelly MJ, Rønnekleiv OK (2009) Control of CNS neuronal excitability by estrogens via membrane-initiated signaling. Mol Cell Endocrinol 308: $17-25$.

Koyano K, Funabiki K, Ohmori H (1996) Voltage-gated ionic currents and their roles in timing coding in auditory neurons of the nucleus magnocellularis of the chick. Neurosci Res 26:29-45.

Lachica EA, Rübsamen R, Zirpel L, Rubel EW (1995) Glutamatergic ihibition of voltage-operated calcium channels in the avian cochlear nucleus. J Neurosci 15:1724-1734.

Lian J, Bikson M, Sciortino C, Stacey WC, Durand DM (2003) Local suppression of epileptiform activity by electrical stimulation in rat hippocampus in vitro. J Physiol 547:427-434.

Liu X, Onaka T, Yagi K (2001) Facilitation of Ca2 + store-dependent noradrenaline release after an $\mathrm{N}$-methyl-D-aspartate receptor antagonist in the rat supraoptic nucleus. J Neuroendocrinol 13:894-904.

Lu Y (2009) Regulation of glutamatergic and GABAergic neurotransmission in the chick nucleus laminaris: role of $\mathrm{N}$-type calcium channels. Neuroscience 164:1009-1019.

Lu Y, Rubel EW (2005) Activation of metabotropic glutamate receptors inhibits high-voltage-gated calcium channel currents of chicken nucleus magnocellularis neurons. J Neurophysiol 93:1418-1428.

Mhyre AJ, Dorsa DM (2006) Estrogen activates rapid signaling in the brain: role of estrogen receptor $\alpha$ and estrogen receptor $\beta$ in neurons and glia. Neuroscience 138:851-858.

Milner TA, McEwen BS, Hayashi S, Li CJ, Reagan LP, Alves SE (2001) Ultrastructural evidence that hippocampal alpha estrogen receptors are located at extranuclear sites. J Comp Neurol 429:355-371.

Mukai H, Takata N, Ishii HT, Tanabe N, Hojo Y, Furukawa A, Kimoto T, Kawato S (2006) Hippocampal synthesis of estrogens and androgens which are paracrine modulators of synaptic plasticity: synaptocrinology. Neuroscience 138:757-764.

Naftolin F, Horvath TL, Jakab RL, Leranth C, Harada N, Balthazart J (1996) Aromatase immunoreactivity in axon terminals of the vertebrate brain. An immunocytochemical study on quail, rat, monkey and human tissues. Neuroendocrinology 63:149-155.

Okada M, Wada K, Kiryu K, Kawata Y, Mizuno K, Kondo T, Tasaki H, Kaneko S (1998) Effects of Ca2 + channel antagonists on striatal dopamine and DOPA release, studied by in vivo microdialysis. Br J Pharmacol 123:805-814.

Olivera BM, Miljanich GP, Ramachandran J, Adams ME (1994) Calcium channel diversity and neurotransmitter release: the omega-conotoxins and omega-agatoxins. Annu Rev Biochem 63:823-867.

Peterson RS, Yarram L, Schlinger BA, Saldanha CJ (2005) Aromatase is presynaptic and sexually dimorphic in the adult zebra finch brain. Proc Biol Sci 272:2089-2096.

Remage-Healey L, Bass AH (2006) A rapid neuromodulatory role for steroid hormones in the control of reproductive behavior. Brain Res 1126:27-35.
Remage-Healey L, Bass AH (2007) Plasticity in brain sexuality is revealed by the rapid actions of steroid hormones. J Neurosci 27:1114-1122.

Remage-Healey L, Maidment NT, Schlinger BA (2008) Forebrain steroid levels fluctuate rapidly during social interactions. Nat Neurosci 11: 1327-1334.

Remage-Healey L, Oyama RK, Schlinger BA (2009) Elevated aromatase activity in forebrain synaptic terminals during song. J Neuroendocrinol 21:191-199.

Remage-Healey L, Coleman MJ, Oyama RK, Schlinger BA (2010) Brain estrogens rapidly strengthen auditory encoding and guide song preference in a songbird. Proc Natl Acad Sci U S A 107:3852-3857.

Rohmann KN, Schlinger BA, Saldanha CJ (2007) Subcellular compartmentalization of aromatase is sexually dimorphic in the adult zebra finch brain. Dev Neurobiol 67:1-9.

Rudick CN, Woolley CS (2001) Estrogen regulates functional inhibition of hippocampal CA1 pyramidal cells in the adult female rat. J Neurosci 21:6532-6543.

Sasaki A, Sotnikova TD, Gainetdinov RR, Jarvis ED (2006) Social contextdependent singing-regulated dopamine. J Neurosci 26:9010-9014.

Schlinger BA, Callard GV (1989) Localization of aromatase in synaptosomal and microsomal subfractions of quail (Coturnix-Coturnix-Japonica) brain. Neuroendocrinology 49:434-441.

Srivastava DP, Woolfrey KM, Liu F, Brandon NJ, Penzes P (2010) Estrogen receptor ss activity modulates synaptic signaling and structure. J Neurosci 30:13454-13460.

Stanley EF, Goping G (1991) Characterization of a calcium current in a vertebrate cholinergic presynaptic nerve terminal. J Neurosci 11:985-993.

Thompson TL, Moss RL (1994) Estrogen regulation of dopamine release in the nucleus-accumbens-genomic-mediated and nongenomic-mediated effects. J Neurochem 62:1750-1756.

Tremere LA, Jeong JK, Pinaud R (2009) Estradiol shapes auditory processing in the adult brain by regulating inhibitory transmission and plasticityassociated gene expression. J Neurosci 29:5949-5963.

Wada T, Abe J, Minami T, Masuko T, Ichida S (2003) A confirmation of I-125-omega-conotoxin labeled sites in a crude membrane fraction from chick brain as the alpha(1) subunit of N-type calcium channels. Neurochem Res 28:705-710.

Westerink BH (1995) Brain microdialysis and its application for the study of animal behaviour. Behav Brain Res 70:103-124.

Wong M, Moss RL (1992) Long-term and short-term electrophysiological effects of estrogen on the synaptic properties of hippocampal CAl neurons. J Neurosci 12:3217-3225.

Woolley CS (2007) Acute effects of estrogen on neuronal physiology. Annu Rev Pharmacol Toxicol 47:657-680.

Xu Y, Traystman RJ, Hurn PD, Wang MM (2003) Neurite-localized estrogen receptor-alpha mediates rapid signaling by estrogen. J Neurosci Res 74:1-11.

Yawo H, Momiyama A (1993) Re-evaluation of calcium currents in presynaptic and postsynaptic neurones of the chick ciliary ganglion. J Physiol 460:153-172. 